\title{
The effect of feeding with hemp and Camelina cakes on the fatty acid profile of duck muscles
}

\author{
Robertas Juodka $^{1}$, Remigijus Juska ${ }^{1}$, Violeta Juskiene ${ }^{1}$, Raimondas Leikus ${ }^{2}$, Daiva Stankeviciene ${ }^{1}$, and \\ Rasa Nainiene ${ }^{3}$ \\ ${ }^{1}$ Department of Ecology, Animal Science Institute of Lithuanian University of Health Sciences, \\ R. Zebenkos 12, 82317 Baisogala, Radviliskis district, Lithuania \\ ${ }^{2}$ Department of Animal Feeding and Feedstuffs, Animal Science Institute of Lithuanian University \\ of Health Sciences, R. Zebenkos 12, 82317 Baisogala, Radviliskis district, Lithuania \\ ${ }^{3}$ Department of Animal Breeding and Reproduction, Animal Science Institute of Lithuanian University \\ of Health Sciences, R. Zebenkos 12, 82317 Baisogala, Radviliskis district, Lithuania
}

Correspondence: Robertas Juodka (robertasjuodka@gmail.com)

Received: 4 October 2017 - Revised: 6 June 2018 - Accepted: 17 June 2018 - Published: 19 July 2018

\begin{abstract}
Camelina (Camelina sativa L. Crantz) and hemp (Cannabis sativa L.) seed cakes are rich sources of $\mathrm{n}-3$ polyunsaturated fatty acids (PUFAs). This study was carried out to investigate the effects of Camelina and hempseed cakes in the diet of ducks on the intramuscular fatty acid profile. Male ducks $(n=99)$ were randomly allocated to 3 dietary treatments: Control or C group (wheat-soybean-meal-barley-based diet with 15-20\% rapeseed cake), Experimental 1 or HEM group (with hempseed cake added at 15-20\% instead of rapeseed cake), and Experimental 2 or CAM group (with Camelina cake added at 15-20\% instead of rapeseed cake). All groups received the diets ad libitum. At 49 days of age, six ducks from each group were slaughtered for analysis of the fatty acid composition in the breast and leg muscles.

Feeding ducks with the diet enriched with Camelina cake resulted in significantly higher amounts of n$3 \alpha$-linolenic fatty acid (ALA) $(P \leq 0.01)$ and total n-3 PUFA $(P \leq 0.01)$ in breast and leg muscles, while eicosatrienoic fatty acid (ETE) $(P \leq 0.01)$ was higher in the leg muscle. The ratios of n-6/n-3 and linoleic $/ \alpha-$ linolenic fatty acids $(P \leq 0.01)$ decreased significantly compared to the Control and HEM groups of ducks.

Feeding ducks with the diet enriched with hempseed cake resulted in significantly higher amounts of linoleic (LA) $(P \leq 0.01)$, total n-6 PUFA $(P \leq 0.05-P \leq 0.01)$ and n-6 $\gamma$-linolenic (GLA) $(P \leq 0.01)$ fatty acid.

Our study showed that using Camelina cake as supplementation in duck diets opens a possibility to develop functional food, i.e. meat with a significantly higher content of ALA, total n-3 PUFA and the lowest ratios of $\mathrm{n}-6 / \mathrm{n}-3$ fatty acids in ducks' muscles. A duck diet with hempseed cake produces exceptional-quality meat with an enriched content of n-6 GLA.
\end{abstract}

\section{Introduction}

The supply of all kinds of poultry in the European market is very high. One of the most important aspects of consumer's choice of meat is the benefit to health. Duck is an alternative to the widespread use of chicken and turkey. The studies by Qiao et al. (2002), Wawro et al. (2004), Galal et al. (2011) and Juodka et al. (2016) indicated that the content of intramuscular fat in the breast muscles of ducks is higher than that of chicken and turkey meat. Different in- tramuscular fatty acids have a different influence on human health. Some of them, like saturated fatty acids (SFAs), might boost the development of various cancers and coronary heart diseases, whereas others might act as a preventive measure or are necessary for the proper functioning of the organism (Hu et al., 1999; Gogus and Smith, 2010). It is indicated that the polyunsaturated fatty acids (PUFAs) / SFA ratio in food should be above 0.4 and the ratio of n- 6 / n-3 PUFA should be less than 4 (Wood et al., 2003). 
The composition of fatty acids in the muscles of ducks is not favourable to human health. Under standard feeding conditions, total SFA compared to monounsaturated fatty acids (MUFAs) and PUFA is high and accounts for up to $49.4 \%$ (Kokoszynski and Bernacki, 2010; Kokoszynski, 2011). Meanwhile, n-3 PUFA in the breast muscles is very low; only traces have been reported by Witak (2008). In breast and leg muscles, the PUFA / SFA ratio ranged from 0.22 to 0.42 (Kokoszynski, 2011) and n-6/n-3 ratios ranged from 7.08 to 10.07 (Witak, 2008). Nguyen et al. (2003) indicated that the composition of intramuscular fatty acids in monogastric animals depends on their feed composition. The production of duck meat with higher n-3 PUFA fatty acid compositions requires enrichment of the diet with ingredients containing higher than usual amounts of n-3 PUFA. Currently nutritional strategies have been developed to produce chicken meat or eggs with higher n-3 PUFA content by using flaxseed or marine oils. However, these oils reduce both sensory qualities, due to some additional odour, and shelf life of meat due to the accelerated process of lipid oxidation (Aziza et al., 2010). Fatty acid modification of duck meat has received little attention by researchers compared to other poultry (Shawkat et al., 2007).

By supplementation of duck feeds with 1-1.6\% rapeseed oil, researchers reported $\alpha$-linolenic (C18:3n-3) (ALA) 1$1.62 \%$ content and n-6/n-3 (3.27-5.23) ratios in the breast muscles of ducks (Woloszyn et al., 2005, 2006, 2011). Rapeseed oil in the feed for ducks was beneficial to human health due to better intramuscular fat composition of meat.

Cakes from various oily plants are used in animal feeding. Camelina (Camelina sativa L. Crantz) has been cultivated in Europe for over 2000 years for oil and livestock fodder. Camelina oil cake is the object of interest as a byproduct from biofuel production. Camelina oil cake contains from 16.28 to $29 \%$ ALA (Sampath, 2009; Cherian, 2012), and the n-6 / n-3 PUFA ratio in Camelina sativa seeds is 0.63 (Ciurescu et al., 2016). Due to antioxidants from the group of tocopherols, Camelina oil remains stable for up to 6 months (Abramović et al., 2007).

Another oilseed plant, hemp (Cannabis sativa L.), has recently also become a matter of interest in agriculture and industry (Jing et al., 2017). After creating hemp varieties with a lower amount of tetrahydrocannabinoids, the prohibition on growing hemp was lifted and hemp crop areas increased. Hemp oil is used in pharmaceutics, chemistry and the food industry (Callaway, 2004). Hempseed cake, which is a byproduct of oil production, has a high amount of PUFA (Da Porto et al., 2012). The composition of the fatty acids in the above cakes allows us to think that the use of these cakes for feeding ducks might improve the fatty acid composition of muscles. However, the data are insufficient regarding the use of the cakes for feeding ducks and regarding a significant credible effect on the fatty acid composition of muscles.
The purpose of our study was to modify the composition of intramuscular fat in the breast and leg muscles of Pekin ducks by using different oily plant cakes rich in n-3 PUFA.

\section{Materials and methods}

\subsection{Animal management and study design}

The study was carried out on the experimental farm of the Animal Science Institute of the Lithuanian University of Health Sciences. The investigations were conducted in accordance with the law of the Republic of Lithuania for animal welfare and handling, Law No. IX-2271 (Seimas of the Republic of Lithuania, 2012) and a sub-statutory act by the State Food and Veterinary Service of the Lithuanian Republic regarding the confirmation of the order on animals for experiments, research, storage, maintenance and operating requirements (State Food and Veterinary Service, 2012) and international guidelines, Directive 2010/63/EU in Europe.

Ninety-nine Pekin male ducks were obtained from a commercial hatchery, as hatched, and allotted to three dietary treatment groups with three replicates of 11 ducks, each. The treatments were as follows: Control (C) group (wheatsoybean-meal-barley-based diet supplemented with $15 \%$ rapeseed cake from day 0 to 23 and $20 \%$ rapeseed cake from day 24 to 49); Experimental 1 (HEM) group (supplemented with hempseed cake at 15-20\% instead of rapeseed cake); Experimental 2 (CAM) group (supplemented with Camelina cake at 15-20\% instead of rapeseed cake) The diet composition is given in Table 1.

The birds were accommodated in three pens and housed in a controlled environment. The stocking rate was 15 for 1 day-old ducks and 10 for 21-day-old ducks per square metre of the poultry house. The litter thickness amounted to $10 \mathrm{~cm}$. The temperatures for the ducks' growth were as follows: under the brooder, $30-32{ }^{\circ} \mathrm{C}$; week $2,29-30{ }^{\circ} \mathrm{C}$; and the last week in the poultry house, $20^{\circ} \mathrm{C}$.

The feeds were analysed for dry matter content by ovendrying at $105^{\circ} \mathrm{C}$ up to constant weight; crude protein was analysed by the Kjeldhal method; crude fibre was analysed by the Fibercap method; calcium was analysed by the method of atomic absorption using cesium chloride and aluminum nitrate; phosphorus was analysed by the photometric method using a molibdovanadate reagent (AOAC, 1990). Rapeseed, hempseed and Camelina cakes were analysed for the fatty acid composition.

During the experimental period, water and feed were provided ad libitum. All the birds were reared under the same conditions. The distance to both the feed and water per one 1-day old duck was $2 \mathrm{~cm}$.

At the age of 49 days, six ducks from each group were selected for control slaughtering. Prior to slaughter, the birds had not been fed for $12 \mathrm{~h}$. The carcasses were anatomically dissected according to the methodological recommendation of anatomic carcass dissection and organoleptic evaluation of 
Table 1. Diet composition used in the trial.

\begin{tabular}{|c|c|c|c|c|c|c|}
\hline \multirow[t]{2}{*}{ Specification } & \multicolumn{2}{|c|}{ Control group (C) } & \multicolumn{2}{|c|}{ Experimental 1 (HEM) } & \multicolumn{2}{|c|}{ Experimental 2 (CAM) } \\
\hline & until 23 days & over 23 days & until 23 days & over 23 days & until 23 days & over 23 days \\
\hline \multicolumn{7}{|l|}{ Ingredients, $\%$} \\
\hline Barley & 18 & 15 & 18 & 15 & 18 & 15 \\
\hline Wheat & 48.2 & 52.1 & 49.5 & 53.8 & 49 & 53.1 \\
\hline Soybean oil meal & 13.4 & 7.5 & 12.1 & 5.8 & 12.6 & 6.5 \\
\hline Rapeseed cakes & 15 & 20 & - & - & - & - \\
\hline Hemp cakes & - & - & 15 & 20 & - & - \\
\hline Camelina cakes & - & - & - & - & 15 & 20 \\
\hline Monocalcium phosphate & 1 & 1 & 1 & 1 & 1 & 1 \\
\hline Premix & 3 & 3 & 3 & 3 & 3 & 3 \\
\hline Feed chalk & 1.2 & 1.2 & 1.2 & 1.2 & 1.2 & 1.2 \\
\hline Mycotoxin binder Mycofix ${ }^{\circledR}$ Plus & 0.2 & 0.2 & 0.2 & 0.2 & 0.2 & 0.2 \\
\hline \multicolumn{7}{|l|}{ Calculated nutrients } \\
\hline Dry matter, kg & 0.87 & 0.87 & 0.87 & 0.87 & 0.87 & 0.87 \\
\hline Metabolizable energy, MJ & 10.5 & 10.5 & 11.0 & 11.2 & 10.6 & 10.6 \\
\hline Crude protein, $g$ & 184.0 & 173.3 & 183.9 & 173.3 & 183.9 & 173.5 \\
\hline Lysine, $g$ & 10.9 & 10.1 & 9.8 & 8.6 & 10.8 & 9.9 \\
\hline Methionine + cysteine, $g$ & 5.5 & 5.7 & 5.2 & 5.2 & 5.3 & 5.4 \\
\hline Threonine, g & 6.6 & 6.4 & 6.1 & 5.7 & 6.7 & 6.4 \\
\hline Tryptophan, g & 2.2 & 2.1 & 1.8 & 1.6 & 2.2 & 2.1 \\
\hline Crude fibre, $\mathrm{g}$ & 44.9 & 44.9 & 72.3 & 81.4 & 46.3 & 46.8 \\
\hline Calcium, $\mathrm{g}$ & 14.0 & 14.1 & 13.4 & 13.4 & 13.9 & 13.9 \\
\hline Phosphorus, g & 7.9 & 8.1 & 8.5 & 8.9 & 7.6 & 7.7 \\
\hline
\end{tabular}

The composition premix per kilogram: calcium $-194.7 \mathrm{~g} \mathrm{~kg}^{-1} ;$ phosphorus $-40.4 \mathrm{~g} \mathrm{~kg}^{-1} ; \mathrm{Na}-42.7 \mathrm{~g} \mathrm{~kg}^{-1} ; \mathrm{Fe}-2000 \mathrm{mg} \mathrm{kg}{ }^{-1} ; \mathrm{Cu}_{-} 820 \mathrm{mg} \mathrm{kg}{ }^{-1} ; \mathrm{Mn}^{-} 1000 \mathrm{mg} \mathrm{kg}{ }^{-1}$; $\mathrm{Zn}-5000 \mathrm{mg} \mathrm{kg}^{-1} ; \mathrm{I}-50 \mathrm{mg} \mathrm{kg}^{-1}$; Se $-10 \mathrm{~m} \mathrm{~kg}^{-1}$; retinol - 233450 international units; cholecalciferol - 50 025 international units; $\alpha-$ tocopherol acetate -

$2986 \mathrm{mg} \mathrm{kg}^{-1}$; vit. $\mathrm{K} 3-67 \mathrm{mg} \mathrm{kg}^{-1}$; thiamine $-40 \mathrm{mg} \mathrm{kg}^{-1}$; riboflavin $-167 \mathrm{mg} \mathrm{kg}^{-1}$; vit. B5 (pantothenic acid) - $657 \mathrm{mg} \mathrm{kg}^{-1}$; pyridoxine - $100 \mathrm{mg} \mathrm{kg}-1$; cobalamin -

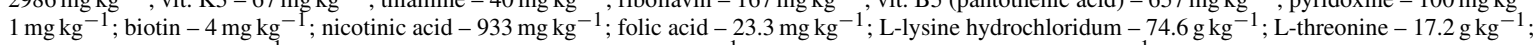

DL-methionine $-0.3 \mathrm{~g} \mathrm{~kg}^{-1}$; endo- 1,3 (4)- $\beta$-glucanase - $3225.33 \mathrm{~mL} \mathrm{~kg}^{-1}$; endo- $1,4-\beta$-xylanase $-3656.67 \mathrm{~mL} \mathrm{~kg}^{-1}$.

poultry (Lukashenko et al., 1984). Animals were slaughtered in a commercial EU-licensed abattoir. At slaughter, $50 \mathrm{~g}$ of breast and leg muscles was taken from every duck for the analysis of fatty acid composition.

\subsection{Fatty acid analyses}

The extraction of lipids for fatty acid analysis was performed with a mixture of two volumes of chloroform (Chromasolv Plus for high-performance liquid chromatography (HPLC) containing $0.5-1.0 \%$ ethanol as stabilizer) and one volume of methanol (Chromasolv for HPLC $\geq 99.9 \%$ ) as described by Folch et al. (1957). The sample of $2 \mathrm{~g}$ meat was mixed with $40 \mathrm{~mL}$ chloroform/methanol mixture and homogenized using disperser $T 18\left(\mathrm{IKA}^{\circledR}-\right.$ Werke GmbH\&Co.KG, Germany). After filtration, $20 \mathrm{~mL}$ of $0.74 \% \mathrm{KCl}$ (SigmaAldrich, Reagent Plus $\geq 99.0 \%$ ) solution was added and allowed to stand for 10-12 h. Then, the bottom layer was collected by syringe into a $15 \mathrm{~mL}$ test tube and evaporated under vacuum at $50^{\circ} \mathrm{C}$. Methylation of the samples was performed using a sodium methoxide $25 \mathrm{wt} \%$ solution in methanol (Sigma-Aldrich). Then, $5 \mathrm{~mL}$ sodium methoxide was added to the sample and stirred. After $1 \mathrm{~h}, 7 \mathrm{~mL} \mathrm{HCl}, 6 \mathrm{~mL}$ hexane (Sigma-Aldrich, Chromasolv for HPLC $\geq 97.0 \%$ ) and $2 \mathrm{~mL}_{2} \mathrm{O}$ were added. The top layer was transferred into a new test tube and evaporated. The fatty acid methyl esters (FAMEs) were analysed using a gas-liquid chromatograph (GC-2010 Shimadzu) fitted with flame ionization detector. The separation of methyl esters of fatty acids was effected on the capillary column Rt $2560(100 \mathrm{~m} \times 0.25 \mathrm{~mm} \times 0.2 \mu \mathrm{m}$; Restek, Bellefonte, PA, USA) by temperature programming from 140 to $240^{\circ} \mathrm{C}$. The column was operated at $140^{\circ} \mathrm{C}$ for $5 \mathrm{~min}$, and then the temperature was increased to $240^{\circ} \mathrm{C}$ at $4{ }^{\circ} \mathrm{C} \mathrm{min}^{-1}$ and held for $20 \mathrm{~min}$. The temperatures of the injector and detector were held, respectively, at 240 and $260^{\circ} \mathrm{C}$. The rate of flow of carrier gas (nitrogen) through the column was $1.06 \mathrm{~mL} \mathrm{~min}^{-1}$. The peaks were identified by comparison with the retention times of the standard fatty acids methyl esters 37 Component FAME Mix and trans FAME MIX $k 110$ (Supelco, USA). The relative proportion of each fatty acid was expressed as the relative percentage of the sum of the total fatty acids using the GC Solution software for Shimadzu gas chromatograph workstations. 


\subsection{Lipid quality indices analyses}

Lipid quality indices, i.e. the atherogenic index (AI) and the thrombogenic index (TI), (Ulbricht and Southgate, 1991; Okrouhlá et al., 2013), and hypocholesterolemic / hypercholesterolemic $(h / H)$ (Fernández et al., 2007) indices were calculated on the basis of fatty acid analysis data as follows:

$$
\begin{aligned}
& -\mathrm{AI}=(\mathrm{C} 12: 0+4 \times \mathrm{C} 14: 0 \\
& +\mathrm{C} 16: 0) /(\text { MUFA + PUFA); } \\
& \text { - } \mathrm{TI}=(\mathrm{C} 14: 0+\mathrm{C} 16: 0+\mathrm{C} 18: 0) /(0.5 \times \text { MUFA } \\
& +(0.5 \times \mathrm{n}-6 \text { PUFA }+3 \times \mathrm{n}-3 \text { PUFA } \\
& + \text { n-3 / n-6PUFA); } \\
& \text { - } h / H=[(\text { sum of C18:1n-9, C18:1n-7, C18:2n-6, } \\
& \text { C18 : 3n-6, C18 : 3n-3, C20 : 3n-6, C20 : 4n-6, } \\
& \text { C20 : 5n-3, C22: 4n-6, C22: 5n-3 and } \\
& \text { C22: 6n-3) / (sum of C14:0 and C16:0)]. }
\end{aligned}
$$

All analytical studies were carried out at the Analytical Laboratory of the Lithuanian University of Health Sciences Animal Science Institute.

\subsection{Statistical analyses}

The statistical evaluation of the results was performed using descriptive statistics. Statistical analysis was performed using the statistical software package Statistica, version 7 (Data Analysis Software System, Version 7.0; StatSoft, Inc., Tulsa, OK, USA). The results are expressed as mean values and standard deviation (SD). The individual duck served as the experimental unit for the fatty acid composition of meat. Statistical data were analysed using standard methods of oneway analysis of variance (ANOVA). When ANOVA detected differences between groups, the significance of differences between specific groups (C-CAM; C-HEM; HEM-CAM) was determined with a Student's $t$ test. Differences were considered statistically significant at $P \leq 0.05$.

\section{Results}

The highest content of total SFA and palmitic (C16:0) fatty acid was found in the breast muscles of HEM group ducks, and it was 1.04 times $(P \leq 0.05)$ higher in comparison with $\mathrm{C}$ group ducks, though hemp cake had the lowest total SFA content (Table 2). In the leg muscles of the CAM group, total SFA and palmitic (C16:0) fatty acid was 1.06 times higher $(P \leq 0.01)$ when compared with $\mathrm{C}$ group ducks (Tables 3, 4). Meanwhile, the lowest total SFA content was found in the muscles of $\mathrm{C}$ ducks fed with the diet supplemented with rapeseed cake that has the highest total SFA.

Feeding ducks with the diet supplemented with hemp cake resulted in 1.14 times higher content of myristic (C14:0) fatty acid $(P \leq 0.05)$ in the leg muscles, but the content of pentadecanoic $(\mathrm{C} 15: 0)$ and margaric $(\mathrm{C} 17: 0)$ fatty acids decreased in both groups of muscles in comparison with $\mathrm{C}$ group ducks.

The content of arachidic (C20:0) acid increased by 1.38 and 1.67 times, respectively, in the breast and leg muscles of ducks fed with Camelina cake in comparison with $\mathrm{C}$ group ducks $(P \leq 0.01)$. Meanwhile, the content of margaric acid (C17:0) in the leg muscles of CAM group ducks decreased and was 1.22 times $(P \leq 0.05)$ lower in comparison with $\mathrm{C}$ group ducks.

There was no significant difference for the total MUFA content in the breast muscles between the groups. By contrast, in the leg muscles of HEM and CAM group ducks the total MUFA content was found to be 1.06 times $(P \leq 0.05)$ and 1.08 times $(P \leq 0.01)$ lower than that of $\mathrm{C}$ group ducks, respectively.

Ducks fed with the diet supplemented with Camelina cake received 2.05 and 1.66 times more total n-3 PUFA than the ducks fed, respectively, with rapeseed and hempseed cake. Therefore, the most significant changes were found in the meat of ducks from the CAM group both by the total n-3 PUFA and by the individual n-3 PUFA.

Total n-3 PUFA content in the breast muscles of CAM group ducks was 1.70 times $(P \leq 0.01)$ higher than the total n-3 PUFA content in the breast muscles of $\mathrm{C}$ group ducks. Moreover, leg muscles of ducks from the CAM group had 2.15 times $(P \leq 0.01)$ higher total n-3 PUFA in comparison with ducks from the $\mathrm{C}$ group.

In our study, among n-3 PUFAs, ALA was found to be the highest in its content. In the breast and leg muscles of CAM group ducks, the content of ALA was, respectively, 1.83 times $(P \leq 0.01)$ and 2.42 times $(P \leq 0.01)$ higher in comparison with $\mathrm{C}$ group ducks.

The highest eicosatrienoic (C20:3n-3; ETE) content was detected in the breast muscles of ducks from the CAM group, where it was 2 times $(P \leq 0.01)$ higher than that of $C$ group ducks, and in the leg muscles where the contents was 4.33 times $(P \leq 0.01)$ higher than those of $\mathrm{C}$ group rapeseed ducks.

In our study, the highest long-chain n-3 PUFA (sum of ETE, eicosapentaenoic (C20 : 5n-3; EPA), docosapentaenoic (C22 : 5n-3; DPA) and docosahexaenoic (C22 : 6n-3; DHA)) content was detected in the leg muscles of ducks from the CAM group, and that content was, respectively, 1.45 and 1.50 times $(P \leq 0.01)$ higher when compared with $\mathrm{C}$ and HEM group ducks.

Neither a total $\mathrm{n}-6$ nor a linoleic $(\mathrm{C} 18: 2 \mathrm{n}-6$; LA) increase was detected in the meat of ducks from the CAM group; however, there were changes in some long-chain (LC) n-6 fatty acids. The muscles of CAM group ducks had a higher content of eicosadienoic (C20:2n-6) fatty acid than the meat of $\mathrm{C}$ and HEM group ducks. Meanwhile, a higher amount of docosadienoic (C22:2n-6) fatty acid was found in the leg muscles of CAM group ducks in comparison with $\mathrm{C}$ group ducks. 
Table 2. Composition of fatty acid content of rapeseed, hempseed and Camelina cakes ( $\%$ of total fatty acids).

\begin{tabular}{|c|c|c|c|}
\hline Fatty acid & Rapeseed cake & Hempseed cake & Camelina cake \\
\hline Myristic (C14:0) & 0.68 & 0.07 & 0.11 \\
\hline Pentadecanoic (C15:0) & 0.16 & 0.00 & 0.04 \\
\hline Palmitic (C16:0) & 12.41 & 4.46 & 7.05 \\
\hline Margaric (C17:0) & 0.21 & 0.06 & 0.06 \\
\hline Stearic $(\mathrm{C} 18: 0)$ & 2.21 & 1.76 & 2.37 \\
\hline Arachidic (C20 : 0) & 0.33 & 0.71 & 1.51 \\
\hline Heneicosanoic $(\mathrm{C} 21: 0)$ & 0.00 & 0.00 & 0.02 \\
\hline Behenic (C22:0) & 0.18 & 0.38 & 0.36 \\
\hline Lignoceric (C24:0) & 0.12 & 0.22 & 0.21 \\
\hline SFA & 16.30 & 7.66 & 11.73 \\
\hline Myristoleic (C14 : 1n-7) & 0.05 & 0.00 & 0.00 \\
\hline Palmitoleic (C16: 1n-7) & 0.98 & 0.15 & 0.22 \\
\hline Hexadecenoic (C16:1n-9) & 0.19 & 0.05 & 0.08 \\
\hline Heptadecenoic (C17 : 1n-9) & 0.20 & 0.06 & 0.05 \\
\hline Vaccenic $(\mathrm{C} 18: 1 \mathrm{n}-7)$ & 5.29 & 0.85 & 1.35 \\
\hline Oleic (C18:1n-9) & 40.99 & 8.27 & 17.11 \\
\hline Elaidic (C18 : $1 n-9$ trans) & 0.18 & 0.06 & 0.00 \\
\hline Eicosenoic (C20:1n-9) & 0.60 & 0.46 & 12.28 \\
\hline Erucic (C22: 1n-9) & 0.09 & 0.00 & 3.20 \\
\hline Nervonic (C24:1n-9) & 0.09 & 0.10 & 0.92 \\
\hline MUFA & 48.66 & 10.00 & 35.21 \\
\hline Linoleic $(C 18: 2 n-6)$ & 21.67 & 59.52 & 24.16 \\
\hline Linolelaidic (C18 : 2n-6trans) & 0.00 & 0.10 & 0.02 \\
\hline Octadecadienoic (C18:2n-6cis, trans) & 0.00 & 0.00 & 0.04 \\
\hline$\gamma-$ Linolenic $(\mathrm{C} 18: 3 \mathrm{n}-6)$ & 0.06 & 4.52 & 0.11 \\
\hline$\alpha$-Linolenic (C18 : 3n-3) & 13.05 & 15.85 & 25.88 \\
\hline Eicosadienoic (C20 : 2n-6) & 0.08 & 1.38 & 1.65 \\
\hline Eicosatrienoic (C20:3n-3) & 0.00 & 0.05 & 0.84 \\
\hline Eicosatrienoic (C20:3n-6) & 0.12 & 0.00 & 0.00 \\
\hline Arachidonic $(\mathrm{C} 20: 4 \mathrm{n}-6)$ & 0.00 & 0.00 & 0.05 \\
\hline Eicosapentaenoic (C20 : 5n-3) & 0.00 & 0.16 & 0.00 \\
\hline Docosadienoic (C22:2n-6) & 0.00 & 0.00 & 0.30 \\
\hline Docosatetranoic (C22: 4n-6) & 0.03 & 0.00 & 0.03 \\
\hline n-6 PUFA & 21.96 & 65.52 & 26.36 \\
\hline n-3 PUFA & 13.05 & 16.06 & 26.72 \\
\hline PUFA / SFA & 2.15 & 10.65 & 4.53 \\
\hline$n-6 / n-3$ & 1.68 & 4.08 & 0.99 \\
\hline
\end{tabular}

SFAs - saturated fatty acids. MUFAs - monounsaturated fatty acids. PUFAs - polyunsaturated fatty acids.

The leg muscles of ducks from the CAM group contained the lowest amount of docosatetraenoic (C22:4n-6) fatty acid, and this content was 1.73 times $(P \leq 0.01)$ lower in comparison with $\mathrm{C}$ group ducks. Ducks, fed with the diet supplemented with hemp cake, received the highest amount of total n-6 PUFA and that was, respectively, 2.98 and 2.49 times higher in comparison with the ducks fed with rapeseed and Camelina cakes. Therefore, the most significant differences in n-6 PUFA were detected in HEM ducks.

The highest amount of LA was detected in the leg muscles of ducks from the HEM group, i.e. the content was 1.22 times $(P \leq 0.01)$ higher than that of $\mathrm{C}$ group ducks. In the breast muscles of HEM group ducks the content of LA was 1.17 times $(P \leq 0.01)$ higher than that detected in $C$ group ducks.
Hemp cake differed from the other oil plant cakes used in the study in its high (4.52\%) content of $\gamma$-linolenic (GLA). Therefore, the content of GLA in the breast muscles of ducks from HEM groups was 2.33 times $(P \leq 0.01)$ higher in comparison with $\mathrm{C}$ group ducks; in the leg muscles of HEM group ducks it was 2.83 times $(P \leq 0.01)$ higher than that of $\mathrm{C}$ group ducks.

In the muscles of HEM ducks, there were no significant changes in individual LC n-6 fatty acids in comparison with the $\mathrm{C}$ group. However, the sum of LC $\mathrm{n}-6$ (eicosadienoic (C20:2n-6), eicosatrienoic (20:3n-6), arachidonic (C20:4n-6), docosadienoic (C22:2n-6) and docosatetraenoic (C22:4n-6)) fatty acids increased and made up $4.02 \%$ in the total fatty acid profile of the breast muscles 
Table 3. The fatty acid composition of duck breast muscles (\% of total fatty acids).

\begin{tabular}{|c|c|c|c|c|c|c|}
\hline \multirow[t]{3}{*}{ Item } & \multicolumn{6}{|c|}{ Groups } \\
\hline & \multicolumn{2}{|c|}{ Control group (C) } & \multicolumn{2}{|c|}{ Experimental 1 (HEM) } & \multicolumn{2}{|c|}{ Experimental 2 (CAM) } \\
\hline & Mean & SD & Mean & SD & Mean & SD \\
\hline Lauric (C12: 0) & 0.02 & 0.00 & 0.02 & 0.00 & 0.02 & 0.01 \\
\hline Myristic (C14 : 0) & 0.40 & 0.02 & 0.44 & 0.05 & 0.42 & 0.05 \\
\hline Pentadecanoic (C15:0) & $0.06^{\mathrm{a}}$ & 0.01 & $0.05^{\mathrm{b}}$ & 0.01 & $0.06^{\mathrm{a}, \mathrm{b}}$ & 0.01 \\
\hline Palmitic (C16:0) & $22.65^{b}$ & 0.36 & $23.44^{\mathrm{a}}$ & 0.64 & $23.18^{\mathrm{a}, \mathrm{b}}$ & 0.88 \\
\hline Margaric (C17 : 0) & $0.12^{\mathrm{a}}$ & 0.01 & $0.10^{\mathrm{b}}$ & 0.02 & $0.11^{\mathrm{a}, \mathrm{b}}$ & 0.02 \\
\hline Stearic (C18:0) & 7.32 & 0.38 & 7.69 & 1.12 & 7.31 & 0.75 \\
\hline Arachidic $(\mathrm{C} 20: 0)$ & $0.08^{\mathrm{B}}$ & 0.01 & $0.09^{\mathrm{b}}$ & 0.01 & $0.11^{\mathrm{A}, \mathrm{a}}$ & 0.01 \\
\hline Heneicosanoic (C21:0) & 0.06 & 0.01 & 0.06 & 0.01 & 0.08 & 0.03 \\
\hline Behenic $(\mathrm{C} 22: 0)$ & 0.33 & 0.04 & 0.36 & 0.12 & 0.27 & 0.07 \\
\hline SFA & $31.04^{\mathrm{b}}$ & 0.51 & $32.25^{\mathrm{a}}$ & 0.92 & $31.55^{\mathrm{a}, \mathrm{b}}$ & 0.98 \\
\hline Palmitoleic (C16 : 1n-7) & 2.70 & 0.18 & 3.01 & 0.49 & 2.78 & 0.50 \\
\hline Vaccenic $(\mathrm{C} 18: 1 \mathrm{n}-7)$ & $2.40^{\mathrm{A}}$ & 0.12 & $1.79^{\mathrm{B}}$ & 0.10 & $1.80^{\mathrm{B}}$ & 0.23 \\
\hline Oleic (C18 : 1n-9) & 45.40 & 2.71 & 40.50 & 4.68 & 42.51 & 1.99 \\
\hline MUFA & 51.74 & 2.74 & 46.61 & 5.08 & 49.49 & 2.46 \\
\hline Linoleic (C18 : 2n-6) & $9.96^{\mathrm{B}}$ & 0.68 & $11.67^{\mathrm{A}}$ & 0.56 & $10.24^{\mathrm{B}}$ & 0.48 \\
\hline Linolelaidic (C18 : 2n-6 trans) & 0.03 & 0.02 & 0.04 & 0.01 & 0.04 & 0.01 \\
\hline Octadecadienoic (C18 : 2n-6 cis, trans) & 0.06 & 0.01 & 0.05 & 0.01 & 0.06 & 0.01 \\
\hline Octadecenoic (C18 : 2n-6 trans, cis) & 0.04 & 0.01 & 0.04 & 0.01 & 0.05 & 0.01 \\
\hline$\gamma$-Linolenic (C18 : 3n-6) & $0.06^{\mathrm{B}}$ & 0.01 & $0.14^{\mathrm{A}}$ & 0.04 & $0.05^{\mathrm{B}}$ & 0.01 \\
\hline$\alpha$-Linolenic (C18:3n-3) & $1.80^{\mathrm{B}}$ & 0.57 & $1.90^{\mathrm{B}}$ & 0.14 & $3.29^{\mathrm{A}}$ & 0.43 \\
\hline Eicosadienoic (C20 : 2n-6) & $0.21^{\mathrm{B}}$ & 0.06 & $0.26^{\mathrm{A}, \mathrm{B}}$ & 0.08 & $0.37^{\mathrm{A}}$ & 0.03 \\
\hline Eicosatrienoic (C20 : 3n-3) & $0.08^{\mathrm{B}}$ & 0.04 & $0.13^{\mathrm{A}, \mathrm{B}}$ & 0.08 & $0.16^{\mathrm{A}}$ & 0.04 \\
\hline Eicosatrienoic (C20: 3n-6) & 0.27 & 0.09 & 0.41 & 0.13 & 0.28 & 0.11 \\
\hline Arachidonic (C20:4n-6) & 2.00 & 0.49 & 2.88 & 1.91 & 1.62 & 0.88 \\
\hline Eicosapentaenoic (C20: 5n-3) & 0.20 & 0.06 & 0.25 & 0.08 & 0.28 & 0.10 \\
\hline Docosadienoic (C22: 2n-6) & 0.01 & 0.01 & 0.02 & 0.02 & 0.03 & 0.02 \\
\hline Docosatetraenoic (C22:4n-6) & 0.34 & 0.08 & 0.45 & 0.27 & 0.25 & 0.13 \\
\hline Docosapentaenoic (C22: 5n-3) & 0.32 & 0.10 & 0.42 & 0.24 & 0.41 & 0.12 \\
\hline Docosahexaenoic (C22: 6n-3) & 0.27 & 0.11 & 0.37 & 0.23 & 0.40 & 0.17 \\
\hline PUFA & 15.50 & 2.08 & 18.89 & 3.22 & 17.37 & 1.66 \\
\hline n-6 PUFA & $12.83^{\mathrm{b}}$ & 1.33 & $15.83^{\mathrm{a}}$ & 2.72 & $12.84^{\mathrm{b}}$ & 1.52 \\
\hline n-3 PUFA & $2.67^{\mathrm{B}}$ & 0.84 & $3.07^{\mathrm{B}}$ & 0.68 & $4.53^{\mathrm{A}}$ & 0.51 \\
\hline PUFA/SFA & 0.50 & 0.06 & 0.58 & 0.09 & 0.55 & 0.06 \\
\hline$n-6 / n-3$ & $5.02^{\mathrm{A}}$ & 0.81 & $5.26^{\mathrm{A}}$ & 0.78 & $2.86^{\mathrm{B}}$ & 0.43 \\
\hline Linoleic / $\alpha$-linolenic & $5.83^{\mathrm{A}}$ & 1.09 & $6.32^{\mathrm{A}}$ & 1.07 & $3.17^{\mathrm{B}}$ & 0.54 \\
\hline Hypocholesterolemic / hypercholesterolemic ratio & $2.62^{\mathrm{A}}$ & 0.06 & $2.45^{\mathrm{B}}$ & 0.07 & $2.51^{\mathrm{A}, \mathrm{B}}$ & 0.12 \\
\hline Atherogenic index & $0.36^{\mathrm{B}}$ & 0.01 & $0.39^{\mathrm{A}}$ & 0.01 & $0.37^{\mathrm{B}}$ & 0.02 \\
\hline Thrombogenic index & $0.75^{\mathrm{a}}$ & 0.03 & $0.78^{\mathrm{a}, \mathrm{b}}$ & 0.04 & $0.69^{b}$ & 0.03 \\
\hline
\end{tabular}

Control (C) - diet with rapeseed cake at 15-20\%; Experimental 1 (HEM) - diet with hempseed cake at 15-20\%; Experimental 2 (CAM) - diet with Camelina cake at $15-20 \%$; SD - standard deviation; SFAs - saturated fatty acids; MUFAs - monounsaturated fatty acids; PUFAs - polyunsaturated fatty acids. ${ }^{\text {a,b }}$ Means in the same row with different superscripts differ significantly at $P \leq 0.05$. A,B Means in the same row with different superscripts differ significantly at $P \leq 0.01$.

of HEM group ducks. That was 1.42 and 1.58 times more than in the $\mathrm{C}$ and CAM groups, respectively. In the leg muscles, these differences were not significant, though in HEM group ducks the total LC n- 6 was the highest and accounted for $1.98 \%$ of total fatty acids, but on the whole that was only 1.05 and 1.21 times more than in the C and CAM groups, respectively.
It should be also noted that in the leg muscles of HEM ducks, the total n-3 and ALA were 1.17 and 1.21 times $(P \leq 0.01)$ higher, respectively, than in the same muscle of $C$ group ducks, but there was no difference for these fatty acids in the breast muscles.

The PUFA / SFA ratio in our trial was highest in both groups of muscles of HEM group ducks, but statistical signif- 
Table 4. The fatty acid composition of duck leg muscles (\% of total fatty acids).

\begin{tabular}{|c|c|c|c|c|c|c|}
\hline \multirow[t]{3}{*}{ Item } & \multicolumn{6}{|c|}{ Groups } \\
\hline & \multicolumn{2}{|c|}{ Control group (C) } & \multicolumn{2}{|c|}{ Experimental 1 (HEM) } & \multicolumn{2}{|c|}{ Experimental 2 (CAM) } \\
\hline & Mean & SD & Mean & SD & Mean & SD \\
\hline Lauric (C12:0) & 0.02 & 0.01 & 0.03 & 0.01 & 0.03 & 0.01 \\
\hline Myristic (C14 : 0) & $0.42^{\mathrm{b}}$ & 0.04 & $0.48^{\mathrm{a}}$ & 0.05 & $0.45^{\mathrm{a}, \mathrm{b}}$ & 0.03 \\
\hline Pentadecanoic (C15:0) & $0.06^{\mathrm{A}}$ & 0.00 & $0.05^{\mathrm{B}}$ & 0.01 & $0.06^{\mathrm{A}}$ & 0.01 \\
\hline Palmitic (C16:0) & $21.36^{\mathrm{B}}$ & 0.34 & $22.19 \mathrm{~A}^{\mathrm{B}}$ & 0.93 & $22.73^{\mathrm{A}}$ & 0.77 \\
\hline Margaric (C17 : 0) & $0.11^{\mathrm{A}, \mathrm{a}}$ & 0.01 & $0.07^{\mathrm{B}}$ & 0.02 & $0.09^{\mathrm{A}, \mathrm{b}}$ & 0.01 \\
\hline Stearic $(\mathrm{C} 18: 0)$ & 6.34 & 0.60 & 6.14 & 0.64 & 6.71 & 0.62 \\
\hline Arachidic (C20 : 0) & $0.06^{\mathrm{B}}$ & 0.00 & $0.06^{\mathrm{B}}$ & 0.01 & $0.10^{\mathrm{A}}$ & 0.01 \\
\hline Heneicosanoic (C21:0) & 0.06 & 0.01 & 0.07 & 0.04 & 0.06 & 0.03 \\
\hline Behenic (C22: 0) & 0.24 & 0.02 & 0.22 & 0.03 & 0.21 & 0.06 \\
\hline SFA & $28.62^{\mathrm{B}}$ & 0.88 & $29.31^{\mathrm{A}, \mathrm{B}}$ & 1.25 & $30.87^{\mathrm{A}}$ & 1.22 \\
\hline Palmitoleic (C16: 1n-7) & $3.48^{\mathrm{A}, \mathrm{B}, \mathrm{b}}$ & 0.24 & $4.10^{\mathrm{A}, \mathrm{a}}$ & 0.53 & $3.15^{\mathrm{B}, \mathrm{b}}$ & 0.30 \\
\hline Vaccenic $(\mathrm{C} 18: 1 \mathrm{n}-7)$ & 2.34 & 0.30 & 2.01 & 0.50 & 1.88 & 0.42 \\
\hline Oleic $(\mathrm{C} 18: 1 \mathrm{n}-9)$ & $48.93^{\mathrm{A}}$ & 1.94 & $45.40^{\mathrm{B}}$ & 0.92 & $44.08^{\mathrm{B}}$ & 1.98 \\
\hline MUFA & $55.95^{\mathrm{A}, \mathrm{a}}$ & 2.17 & $52.69^{\mathrm{A}, \mathrm{B}, \mathrm{b}}$ & 1.36 & $51.85^{\mathrm{B}, \mathrm{b}}$ & 1.88 \\
\hline Linoleic $(\mathrm{C} 18: 2 \mathrm{n}-6)$ & $10.06^{\mathrm{B}}$ & 0.65 & $12.28^{\mathrm{A}}$ & 0.81 & $10.35^{\mathrm{B}, \mathrm{C}}$ & 0.79 \\
\hline Linolelaidic (C18 : 2n-6 trans) & $0.04^{\mathrm{a}}$ & 0.01 & $0.02^{\mathrm{b}}$ & 0.01 & $0.03^{\mathrm{a}, \mathrm{b}}$ & 0.01 \\
\hline Octadecadienoic (C18 : 2n-6 cis, trans) & 0.06 & 0.01 & 0.06 & 0.00 & 0.06 & 0.01 \\
\hline Octadecenoic (C18 : 2n-6 trans, cis) & 0.04 & 0.00 & 0.04 & 0.01 & 0.04 & 0.01 \\
\hline$\gamma$-Linolenic (C18 : 3n-6) & $0.06^{B}$ & 0.03 & $0.17^{\mathrm{A}}$ & 0.02 & $0.05^{\mathrm{B}}$ & 0.00 \\
\hline$\alpha$-Linolenic (C18 : 3n-3) & $1.57^{\mathrm{B}}$ & 0.12 & $1.90^{\mathrm{C}}$ & 0.15 & $3.80^{\mathrm{A}}$ & 0.69 \\
\hline Eicosadienoic (C20 : 2n-6) & $0.17^{\mathrm{B}}$ & 0.03 & $0.21^{\mathrm{B}}$ & 0.03 & $0.35^{\mathrm{A}}$ & 0.04 \\
\hline Eicosatrienoic (C20: 3n-3) & $0.03^{\mathrm{B}}$ & 0.02 & $0.04^{\mathrm{B}}$ & 0.01 & $0.13^{\mathrm{A}}$ & 0.02 \\
\hline Eicosatrienoic (C20: 3n-6) & 0.15 & 0.05 & 0.20 & 0.03 & 0.18 & 0.04 \\
\hline Arachidonic (C20 : 4n-6) & $1.29^{\mathrm{a}, \mathrm{b}}$ & 0.30 & $1.31^{\mathrm{a}}$ & 0.25 & $0.93^{\mathrm{b}}$ & 0.34 \\
\hline Eicosapentaenoic (C20: 5n-3) & 0.11 & 0.02 & 0.11 & 0.02 & 0.17 & 0.07 \\
\hline Docosadienoic (C22: 2n-6) & $0.00^{\mathrm{a}}$ & 0.00 & $0.01^{\mathrm{a}, \mathrm{b}}$ & 0.01 & $0.02^{\mathrm{b}}$ & 0.01 \\
\hline Docosatetraenoic (C22: 4n-6) & $0.26^{\mathrm{A}}$ & 0.06 & $0.25^{\mathrm{A}, \mathrm{B}} \mathrm{a}$ & 0.06 & $0.15^{\mathrm{B}, \mathrm{b}}$ & 0.05 \\
\hline Docosapentaenoic (C22: 5n-3) & $0.28^{\mathrm{a}, \mathrm{b}}$ & 0.07 & $0.25^{\mathrm{b}}$ & 0.05 & $0.32^{\mathrm{a}}$ & 0.04 \\
\hline Docosahexaenoic (C22:6n-3) & $0.19^{\mathrm{a}, \mathrm{b}}$ & 0.05 & $0.18^{\mathrm{b}}$ & 0.04 & $0.25^{\mathrm{a}}$ & 0.05 \\
\hline PUFA & $14.17^{\mathrm{B}}$ & 1.23 & $16.89^{\mathrm{A}}$ & 1.20 & $16.69^{\mathrm{A}}$ & 1.20 \\
\hline n-6 PUFA & $12.00^{\mathrm{B}}$ & 1.03 & $14.41^{A}$ & 1.06 & $12.02^{\mathrm{B}}$ & 0.77 \\
\hline n-3 PUFA & $2.17 \mathrm{~B}^{\mathrm{b}}$ & 0.23 & $2.48^{\mathrm{B}, \mathrm{a}}$ & 0.19 & $4.67^{\mathrm{A}}$ & 0.61 \\
\hline PUFA/SFA & $0.49^{\mathrm{b}}$ & 0.03 & $0.58^{\mathrm{a}}$ & 0.06 & $0.54^{\mathrm{a}, \mathrm{b}}$ & 0.05 \\
\hline$n-6 / n-3$ & $5.54^{\mathrm{A}}$ & 0.35 & $5.82^{\mathrm{A}}$ & 0.35 & $2.60^{\mathrm{B}}$ & 0.30 \\
\hline Linoleic / $\alpha$-linolenic & $6.43^{\mathrm{A}}$ & 0.47 & $6.48^{\mathrm{A}}$ & 0.51 & $2.78^{\mathrm{B}}$ & 0.39 \\
\hline Hypocholesterolemic / hypercholesterolemic ratio & $2.88^{\mathrm{A}}$ & 0.09 & $2.73^{\mathrm{A}, \mathrm{B}}$ & 0.16 & $2.60^{\mathrm{B}}$ & 0.15 \\
\hline Atherogenic index & $0.33^{\mathrm{B}}$ & 0.01 & $0.35^{\mathrm{A}, \mathrm{B}}$ & 0.02 & $0.36^{\mathrm{A}}$ & 0.02 \\
\hline Thrombogenic index & 0.69 & 0.03 & 0.70 & 0.04 & 0.65 & 0.05 \\
\hline
\end{tabular}

Control (C) - diet with rapeseed cake at 15-20\%; Experimental 1 (HEM) - diet with hempseed cake at 15-20\%; Experimental 2 (CAM) - diet with Camelina cake at $15-20 \%$; SD - standard deviation; SFA - saturated fatty acids; MUFA - monounsaturated fatty acids; PUFA - polyunsaturated fatty acids. ${ }^{a}$, b Means in the same row with different superscripts differ significantly at $P \leq 0.05$. A, B Means in the same row with different superscripts differ significantly at $P \leq 0.01$.

icance was determined only in the leg muscles in comparison with $\mathrm{C}$ group ducks $(+0.09 ; P \leq 0.05)$.

In our study, CAM group ducks had the lowest $n-6 / n-3$ ratio. In the breast and leg muscles it was, respectively, -2.40 $(P \leq 0.01)$ and $-2.94(P \leq 0.01)$ lower than that of $\mathrm{C}$ ducks. In our study, the lowest ratio of linoleic / $\alpha$-linolenic fatty acids was found only in both muscles of CAM group ducks, which was $-2.66(P \leq 0.01)$ lower in the breast muscles in comparison with $\mathrm{C}$ group ducks and $-3.65(P \leq 0.01)$ lower in the leg muscles in comparison with $\mathrm{C}$ group ducks.

Ducks from the $\mathrm{C}$ group had the highest $h / H$, which was significantly higher in the breast in comparison with the HEM group $(+0.17 ; P \leq 0.01)$ and in the leg muscles in comparison with CAM group ducks $(+0.28 ; P \leq 0.01)$. 
The lowest AI was determined for both muscles of ducks from the $\mathrm{C}$ group. The AI for the breast muscles of ducks from the $\mathrm{C}$ group was significantly lower than that of HEM group ducks ( $P \leq 0.01)$, and for the leg muscles it was lower than that of CAM group ducks $(P \leq 0.01)$.

Ducks from the CAM group had the lowest TI which was -0.06 lower in the breast muscles in comparison with $\mathrm{C}$ group ducks $(P \leq 0.05)$.

\section{Discussion}

Many studies demonstrated that n-6 PUFA is dominant in the meat of poultry grown using conventional technologies, whereas n-3 PUFA content is low; such an n-6/n-3 ratio in meat is unfavourable for human health. Numerous trials have been conducted worldwide aimed at the modification of poultry meat composition in order for it to be more beneficial to human nutrition. Poultry feed is mostly supplemented with flaxseed, fish oil or algae characterized by a higher n-3 PUFA content (Palmquist, 2009; Kouba and Mourot, 2011). Currently, trials with less widely used Camelina and hemp oil, seed or cakes in the diets have been presented, mostly for chickens (Aronen et al., 2009; Aziza et al., 2010; Ciurescu et al., 2016; Jing et al., 2017). However, no studies were found in the literature about the use of Camelina and hemp in the diets for ducks. Therefore, we have carried out a trial to determine the effect of Camelina and hemp cakes on the fatty acid profile of duck muscles.

Our study indicated that duck feed supplementation with Camelina cake resulted in a meat n-3 PUFA profile more favourable to human health; moreover, the cake used for duck feeding is oil production waste, but it is still high in n-3 PUFA content.

Of all the oil plant cakes used in the study, the highest total n-3 PUFA was detected in the Camelina cake fatty acid profile. Therefore, ducks fed with Camelina cake had a significantly higher deposition of total n-3 PUFA in the meat in comparison with ducks from $\mathrm{C}$ and HEM groups. Higher deposition was influenced mainly by ALA and ETE increase in the meat. Our results agree with the finding of other authors, who used Camelina in the diets for chickens (Aronen et al., 2009; Aziza et al., 2010; Pietras and Orczewska-Dudek, 2013; Ciurescu et al., 2016).

The increase in ALA and ETE in our study was different in different muscles; i.e. it increased from 1.83 to 2 times in the breast muscle and from 2.42 to 4.33 times in the leg muscle in comparison with the control group of ducks. The preferential deposition of ALA and ETE in leg muscles can be explained by the fact that leg muscles have more intramuscular fat than breast muscles (Kokoszynski, 2011). It could be noted that Jing et al. (2017) indicated that the extent of n-3 PUFA enrichments may vary with tissue type and animal species. No increase in other LC n-3 PUFA, except ETE, was found in the meat of ducks from the CAM group in comparison with
C group ducks. However, the comparison of the leg fatty acid profiles of HEM group ducks and CAM ducks indicated that in the latter group a significant increase in DPA and DHA was found. This difference could be explained by the fact that the duck meat in the HEM group contained a higher LA amount. LA, a precursor of n-6 LC fatty acid, competed with ALA for the same elongation-desaturation enzymes necessary for the synthesis of both n-3 and n-6 LC fatty acids (Wood et al., 2008). Ciurescu et al. (2016) reported similar results: the increase not only in total n-3 but also in LC n-3 PUFA as EPA, DPA and DHA was found in his trials with chickens fed with Camelina oil or seeds. However, only the increase in EPA and DHA in the breast meat of chickens was reported by Aziza et al. (2010) and Pietras and OrczewskaDudek (2013) in trials with Camelina meal or oil.

The explanation for these different results may be the use of Camelina cake while in other studies Camelina oil, meal or seeds were used for the enrichment of the poultry diet. Moreover, the studies were conducted with different poultry species and the extent of n-3 PUFA enrichments may differ for different bird species (Palmquist, 2009; Jing et al., 2017).

Higher contents of LC n-3 PUFA (C20-C22) in the meat of ducks from the CAM group in comparison with $\mathrm{C}$ and HEM group ducks could be explained by the fact that Camelina cakes had more ALA, which is a precursor of LC n-3 PUFA. This is in agreement with the findings of Aziza et al. (2010). While the human body has limited possibilities to change ALA to health-promoting LC n-3 PUFA (Burdge and Calder, 2005), food has to be the main source of LC n-3 PUFA.

It has also been found that the use of Camelina cake did not increase either total n-6 PUFA or LA content in meat. Pietras and Orczewska-Dudek (2013) and Ciurescu et al. (2016) did not detect any n-6 PUFA increase in chicken meat when running trials with Camelina. However, Huang et al. (2008) and Kouba and Mourot (2011) reported that the use of plant oils, rich in ALA, changed the fatty acid composition of intramuscular fat and increased not only ALA but also LA. The results from our study indicate that $200 \mathrm{~g}$ of breast meat of CAM group ducks contains $259.9 \mathrm{mg}$ of ALA and $53.7 \mathrm{mg}$ of $\mathrm{EPA}+\mathrm{DHA}$. That is $129.6 \mathrm{mg}$ more of ALA and $19.69 \mathrm{mg}$ more of EPA+DHA in comparison with $\mathrm{C}$ group ducks.

Two hundred grammes of the breast meat of CAM group ducks satisfies the daily requirement of ALA and that of EPA + DHA by, respectively, 25.99 and $42.98 \%$. Correspondingly, $200 \mathrm{~g}$ of the breast meat of ducks from HEM and $\mathrm{C}$ groups satisfies the daily requirement of ALA and EPA+DHA by, respectively, 17.29 and $45.14 \%$ and 13.03 and $27.22 \%$, as indicated by the European Food Safety Authority (EFSA, 2009).

Enrichment of the duck diet with hempseed cake, which had a 2.5-3 times higher content of total n-6 PUFA than Camelina and rapeseed cakes, resulted in a significantly higher content of total n- 6 PUFA and individual n- 6 fatty acids as LA and GLA in the duck meat of HEM group. In 
our study GLA content in the duck muscles of the HEM group was much higher because GLA content in hemp cake accounted for $4.52 \%$. Though this fatty acid is an n-6 PUFA, it is unique in its ability to become a substrate for the conversion to the anti-inflammatory eicosanoids of the socalled series-3 type, which may have anti-inflammatory and anti-cancer properties (Kapoor and Huang, 2006). Other researchers also confirm that hemp oil increases GLA content both in chicken eggs and meat and opens the way to produce functional products (Park et al., 2014; Jing et al., 2017).

However, a statistically significant increase in ALA was found only in the leg meat of ducks from the HEM group in comparison with the $\mathrm{C}$ group.

In our study, no direct connection was found between the SFA amount in the feed and the meat of ducks. The lowest total SFA content was detected in the muscles of control ducks despite the fact that the total SFA in the rapeseed cake used for their feeding was the highest. Meanwhile the ducks fed hempseed cake with the lowest total SFA content had the highest palmitic (C16:0) and total SFA content in their breast muscles. However, the highest total SFA content was detected in the legs of CAM group ducks. This is in agreement with the findings of Aziza et al. (2010) and Pietras and Orczewska-Dudek (2013) in the trials with chickens.

In the leg muscles, total MUFA reduction in CAM and HEM groups ducks was found in comparison with $\mathrm{C}$ group ducks. This is in agreement with the findings of Kouba and Mourot (2011) and Jing et al. (2017). Jing et al. (2017) investigated hemp oil in the diets of chicken and laying hens and found a total MUFA reduction in the egg yolk and thigh muscles. According to Jing et al. (2017), MUFA reduction might be due to the fact that higher total n-3 PUFA could inhibit the activity of $\Delta-9$ desaturase, which is necessary for the formation of MUFA from their precursor (Palmquist, 2009). In our trial, higher palmitic (C16:0) but lower palmitoleic (C16:1n-7) fatty acid content in CAM group ducks could be explained by a lower conversion level of palmitic to palmitoleic. Besides, the Camelina and hempseed cakes used in our study had a, respectively, 2.4 and 5 times lower content of oleic (C18:1n-9) fatty acid than that found in rapeseed cake. Oleic (C18 : 1n-9) fatty acid, which is dominant in MUFA, could affect total MUFA reduction in the leg muscles of CAM and HEM ducks. This agrees with the explanation of Jing et al. (2017), who also reported total MUFA reduction, when the feed contained a lower content of oleic (C18:1n-9) fatty acid.

A higher PUFA / SFA ratio, detected in hempseed cake in comparison with rapeseed cake, influenced the higher PUFA / SFA ratio in the leg muscles of HEM group ducks in comparison with $\mathrm{C}$ ducks. This is in agreement with the findings of Jing et al. (2017) in the studies with chickens and hemp oil in their feed. In our investigation, the PUFA / SFA ratio found in all groups is close to that recommended in human food, i.e. over 0.4 (Department of Health, 1994; Wood et al., 2008). The lowest ratios of n-
$6 / \mathrm{n}-3$ and linoleic $/ \alpha$-linolenic fatty acids were detected in Camelina cake and influenced health-promoting n- $6 / n-$ 3 and linoleic / $\alpha$-linolenic fatty acids ratios in CAM duck muscles. Our data are in agreement with the findings of Aronen et al. (2009), Aziza et al. (2010) and Pietras and Orczewska-Dudek (2013) who used Camelina meal, oil or cake in the diets of broiler chickens. The n- $6 / n-3$ ratio in our investigation in CAM ducks was better than that recommended in human food, i.e. 4-5 or less (Wood and Enser, 1997; Okrouhla et al., 2013).

In food for humans, the most favourable ratio of linoleic / $\alpha$-linolenic fatty acids should be 4.0 (Wood et al., 2003), but in our study a better than recommended ratio was found in the muscles of CAM ducks, i.e 2.78-3.17. In our study, the linoleic / $\alpha$-linolenic fatty acid ratio in the breast muscle of all the treated groups was lower (2.49 to 5.64) than indicated by Woloszyn et al. (2008) in the trials with ducks fed rapeseed oil, and that in the leg muscles ranged from 6.11 to 9.81 .

In summary, the addition of Camelina cake at a level of 15-20\% in the diet of ducks improved ALA, total n-3 PUFA and the ratio of $n-6 / n-3$ in their muscles, compared with the groups that had diets enriched with rapeseed or hempseed cakes.

Supplementation of the feed with hempseed cake increased n-3 PUFA only in the legs of ducks, while total n-6 PUFA increased in both legs and breast muscles. Hempseed cake also increased the content of GLA in duck meat and allows the production of duck meat of exceptional quality.

Data availability. The original data are available upon request to the corresponding author.

Author contributions. RJ defined the research theme, conceived of the research, worked on the analysis and interpretation of results, and provided the final version of paper; REJ conceived of the study and participated in its design and coordination and worked on the interpretation of results; VJ interpreted data, discussed results and drafted the paper; RL formulated the feed mixtures used in the study and monitored ducklings' feeding; DS carried out measurements and sampling on the slaughter line and performed statistical analysis; RN participated in the design of the experiment and helped to draft the paper. All authors have read and approved the final paper.

Competing interests. The authors declare that they have no conflict of interest.

Edited by: Manfred Mielen

Reviewed by: Janina Woloszyn and one anonymous referee 


\section{References}

Abramović, H., Butinar, B., and Nikolić, V.: Changes occurring in phenolic content, tocopherol composition and oxidative stability of Camelina sativa oil during storage, Food. Chem., 104, 903909, 2007.

AOAC: Official methods of analyses of association of analytical chemist, 15th Edn., Washington, DC, USA, 1990.

Aronen, I., Valkonen, E., Tupasela, T., Hiidenhovi, J., and Valaja, J.: The Effect of Camelina sativa cake on fatty acid composition and sensory quality of eggs and broiler meat, in: Proceedings of the 19th European Symposium on the Quality of Poultry Meat, 13th European Symposium on the Quality of Eggs and Egg Products, Turku, Finlaand, 21-25 June 2009, 1-11, 2009.

Aziza, A. E., Quezada, N., and Cherian, G.: Feeding Camelina sativa meal to meat-type chickens: Effects on production performance and tissue fatty acid composition, J. Appl. Poult. Res., 19, 157-168, 2010.

Burdge, G. C. and Calder, P. C.: $\alpha$-linolenic acid metabolism in adult humans: the effects of gender and age on conversion to longer-chain polyunsaturated fatty acids, Eur. J. Lipid. Sci. Tech., 107, 426-439, 2005.

Callaway, J. C.: Hempseed as a nutritional resource: An overview, Euphytica, 140, 65-72, 2004.

Cherian, G.: Camelina sativa in poultry diets: opportunities and challenges, in: Biofuel co-products as livestock feed, Opportunities and challenges, edited by: Harinder, P. S., Makkar, FAO, Rome, Italy, 303-310, 2012.

Ciurescu, G., Ropota, M., Toncea, I., and Habeanu M.: Camelia (Camelina sativa L. Crantz Variety) Oil and Seeds as $n-3$ Fatty Acids Rich Products in Broiler Diets and Its Effects on Performance, Meat Fatty Acid Composition, Immune Tissue Weights, and Plasma Metabolic Profile, J. Agr. Sci. Tech., 18, 315-326, 2016.

Da Porto, C., Decorti, D., and Tubaro, F.: Fatty acid composition and oxidation stability of hemp (Cannabis sativa L.) seed oil extracted by supercritical carbon dioxide, Ind. Crops Prod., 36, 401-404, 2012.

Department of Health: Report on Health and Social Subjects No. 46. Nutritional Aspects of Cardiovascular Disease. Report of the Cardiovascular Review Group Committee on Medical Aspects of Food and Nutrition Policy, HMSO, London, 1994.

EFSA: Scientific opinion of the panel on dietetic products, nutrition and allergies on a request from European Commission related to labelling reference intake values for $n-3$ and $n-6$ polyunsaturated fatty acids, EFSA Journal, 1176, 1-11, 2009.

Fernández, M., Ordonez, J. A., Cambero, I., Santos, C., Pin, C., and de la Hoz, L.: Fatty acid compositions of selected varieties of Spanish ham related to their nutritional implications, Food Chem., 101, 107-112, 2007.

Folch, J., Less, M., and Sloane-Stanley, G. H.: A simple method for isolation and purification of total lipids from animal tissues, J. Biol. Chem., 226, 497-509, 1957.

Galal, A., Ali, W. A. H., Ahmed, A. H. M., Ali, A. H. M., and Ali, K. A. A.: Performance and carcass characteristics of Dumyati, Muscovy, Peking and Sudani ducks breeds, Egyptian J. Anim. Prod., 48, 191-202, 2011.

Gogus, U. and Smith, C. H.: $n-3$ Omega fatty acids: a review of current knowledge, Int. J. Food Sci. Tech., 45, 417-436, 2010.
Hu, F. B., Stampfer, M. J., Manson, J. E., Ascherio, A., Colditz, G. A., and Speizer, F. E.: Dietary saturated fats and their food sources in relation to the risk of coronary heart disease in women, Am. J. Clin. Nutr., 70, 1001-1008, 1999.

Huang, F. R., Zhan, Z. P., Luo, J., Liu, Z. X., and Peng, J.: Duration of dietary linseed feeding affects the intramuscular fat, muscle mass and fatty acid composition in pig muscle, Livest. Sci., 118, 132-139, 2008.

Jing, M., Zhao, S., and House, J. D.: Performance and tissue fatty acid profile of broiler chickens and laying hens fed hemp oil and HempOmegaTM, Poultry Sci., 96, 1809-1819, 2017.

Juodka, R., Nainiene, R., Juskiene, V., Juska, R., and Stuoge, I.: Effects of different amounts of field peas (Pissum sativum L.) in the diets for turkeys on meat qualities, J. App. Anim. Res., 44, 150-157, 2016.

Kapoor, R. and Huang, Y. S.: Gamma linolenic acid: an antiinflammatory omega-6 fatty acid, Curr. Pharm. Biotechnol., 7, 531534, 2006.

Kokoszynski, D.: Evaluation of Meat Traits in Commercial Crossbreeds of Pekin Type Ducks, UTP University of Science and Technology, Bydgoszcz, Poland, Investigation Nr 147, 2011 (in Polish).

Kokoszynski, D. and Bernacki, Z.: Comparison of some meat traits in ducks from two conservative flocks, Arch. Anim. Breed., 53, 484-493, https://doi.org/10.5194/aab-53-484-2010, 2010.

Kouba, M. and Mourot, J.: A review of nutritional effects on fat composition of animal products with special emphasis on $n-3$ polyunsaturated fatty acids, Biochimie, 93, 13-17, 2011

Lukashenko, V. S., Lisenko, M. A., and Stoliar, T. A.: Methodological recommendation of anatomic carcass dissection and organoleptic evaluation of poultry, VASCHNIL, Moscow, 1984 (in Russian).

Nguyen, L. Q., Nuijens, M. C. G. A., Everts, H., Salden, N., and Beyen, A. C.: Mathematical relationships between the intake of $n-6$ and $n-3$ polyunsaturated fatty acids and their contents in adipose tissue of growing pigs, Meat Sci., 65, 1399-1406, 2003.

Okrouhla, M., Stupka, R., Č́tek, J., Šprysl, M., and Brzobohatý, L.: Effect of dietary linseed supplementation on the performance, meat quality, and fatty acid profile of pigs, Czech J. Anim. Sci., 58, 279-288, 2013.

Palmquist, D. L.: Omega-3 fatty acids in metabolism, health, and nutrition and for modified animal product foods, Prof. Anim. Sci., 25, 207-249, 2009.

Park, S. O., Hwangbo, J., Yuh, I. S., and Park, B. S.: Gammalinolenic acid egg production enriched with hemp seed oil and evening primrose oil in diet of laying hens, J. Environ. Biol., 35, 635-640, 2014.

Pietras, M. P. and Orczewska-Dudek, S.: The Effect of Dietary Camelina Sativa Oil on Quality of Broler Chicken Meat, Ann. Anim. Sci., 13, 869-882, 2013.

Qiao, M., Fletcher, D. L., Nortcutt, J. K., and Smith, D. P.: The relationship between raw broiler breast meat color and composition, Poultry Sci., 81, 422-427, 2002.

Sampath, A.: Chemical Characterization of Camelina seed oil, Master of Science, the State University of New Jersey, USA, 2009.

Seimas of the Republic of Lithuania: The provisions of the Republic of Lithuania (2012-10-03) for animal welfare and handling. Law No. XI-2271, No. 108-2728, State News, No. 122-6126, Vilnius, Lithuania, 2012 (in Lithuanian). 
Shawkat, A., Kang, G. H., Yang, H. S., Jeong, J. Y., Hwang, Y. H., Park, G. B., and Joo, S. T.: A comparison of meat characteristics between duck and chicken breast, Asian-Aust. J. Anim. Sci., 20, 1002-1006, 2007.

State Food and Veterinary Service: Sub-statutory act by the State Food and Veterinary Service of Lithuanian Republic regarding the confirmation of the order on animals for experiments, research, storage, maintenance and operating requirements, State News, No. 130-6595, Vilnius, Lithuania, 2012 (in Lithuanian).

Statsoft, Inc.: Statistica 2006. Statistica, version 7.0, Tulsa, OK, USA, 2006.

Ulbricht, T. L. V. and Southgate, D. A. T.: Coronary heart disease: seven dietary factors, The Lancet, 338, 985-992, 1991.

Wawro, K., Wilkiewicz-Wawro, E., Kleczek, K., and Brzozowski, W.: Slaughter value and meat quality of Muscovy ducks, Pekin ducks and their crossbreds, and evaluation of the heterosis effect, Arch. Anim. Breed., 47, 287-299, https://doi.org/10.5194/aab47-287-2004, 2004.

Witak, B.: Tissue composition of carcass, meat quality and fatty acid content of ducks of a commercial breeding line at different age, Arch. Anim. Breed., 51, 266-275, https://doi.org/10.5194/aab-51-266-2008, 2008.

Woloszyn, J., Ksiazkewicz, J., Orkusz, A., Skrabka-Blotnicka, T., Biernat, J., and Kisiel, T.: Evaluation of chemical composition of duck's muscles from three conservative flocks, Arch. Geflügelk., 69, 273-280, 2005.
Woloszyn, J., Ksiazkiewicz, J., Skrabka-Blotnicka, T., Haraf, G., Biernat, J., and Kisiel, T.: Comparison of amino acid and fatty acid composition of duck breast muscles from five flocks, Arch. Anim. Breed., 49, 194-204, https://doi.org/10.5194/aab-49-1942006, 2006.

Woloszyn, J., Ksiąźkiewicz, J., Biernat, J., and Okruszek, A.: Nutritional value of duck meat from conservative flocks, Research Papers of Wroclaw University of Economics, 30, 51-61, 2008 (in Polish).

Woloszyn, J., Okruszek, A., Orkusz, A., Werenska, M., Ksiazkiewicz, J., and Grajeta, H.: Effect of duck genotype on leg muscle properties, Arch. Anim. Breed., 54, 649-660, https://doi.org/10.5194/aab-54-649-2011, 2011.

Wood, J. D. and Enser, M.: Factors influencing fatty acids in meat and the role of antioxidants in improving meat quality, Br. J. Nutr., 78, 49-60, 1997.

Wood, J. D., Richardson, R. I., Nute, G. R., Fisher, A. V., Campo, M. M., Kasapidou, E., Sheard, P. R., and Enser, M.: Effects of fatty acids on meat quality: a review, Meat Sci., 66, 21-32, 2003.

Wood, J. D., Enser, M., Fisher, A.V., Nute, G. R., Sheard, P. R., Richardson, R. I., Hughes, S. I., and Whittington, F. M.: Fat deposition,.meat quality: A review, Meat Sci., 78, 343-358, 2008. 